\title{
Preface to the 25th Anniversary Edition
}

\section{MAKING IT UP AS YOU GO ALONG: HOW I WROTE $A R T$ WORLDS}

Art Worlds was published in 1982, after many years of gestation, reading, and poking around. It wasn't a "project" in the usual sense. I didn't investigate this group of artists (jazz players in Chicago) or that artistic community (the theater world of San Francisco) or some specific form of art practiced in such a context. It was, instead, an empirically based consideration of the kinds of questions you can ask and the kinds of operations you would engage in if you set out to study any such phenomenon. So, you could say, Art Worlds is a way of looking at the arts intended to create problems for investigation. My mentor, Everett Hughes, had always warned me to stay away from heavy theorizing, which he said was something to do at the end of your active career, and I believed him. But I had a lot of ideas that were more suitable to a comparative approach than to the close observation of one case, and once I started thinking about them seriously I had no choice but to see where that took me.

From another point of view, of course, Art Worlds is empirical research, although a lot of the empirical materials were gathered or created by other people for their own purposes, and I just used them. I also used a great deal of my own life as raw material. Both are good sources of data and ideas for any piece of research. 
Anyway, here's how it happened.

At the end of the sixties, I had done several large projects on problems of education, focusing on what my colleagues and I called "student culture"-the shared understandings that helped students overcome the difficulties created for them by teachers, school administrators, and others. We had studied student culture in a medical school (Becker et al., 1961), in an undergraduate university (Becker et al., 1968), and in several kinds of vocational education (trade schools and apprenticeships) (Becker; 1972). I had gotten very good at such studies. I had the feeling-surely not accurate, but it's how I felt-that I could go into a new educational setting and, in a few days, know what the results of three years of fieldwork would be. And so I was bored.

I had a chance to escape this dead end in 1970, when I spent a year's leave from Northwestern University at the Center for Advanced Study in the Behavioral Sciences in Palo Alto, California. That's when I consciously began work on Art Worlds. I wanted to do something different, get into a new area of work. I thought that the sociology of art was an underdeveloped field. There wasn't much done in it and what there was was, in my arrogant young view, not very good, much of it, like the books of European thinkers who then wrote most of what was available on the subject (e.g., Goldmann, 1965), heavily philosophical, engaged with classic problems of aesthetics, concerned with judgments of artistic value, and so on. On the other hand, the small amount of work done in the United States was mostly very quantitative and did not really touch on the organization of artistic activity (e.g., Mueller, 1951).

It's an interesting question as to when a piece of research actually begins. In the case of Art Worlds, I could say that it began before I became a sociologist, when I became (or started to become, at the age of eleven or twelve) a piano player. Playing the piano is an experience that colored and continues to color my life and my work as a sociologist. It gave me a lot of what we can reasonably call "data," observations of events, memories of conversations, I knew I could use in my thinking.

I followed the practice of Hughes with respect to doing research and thinking about its results, which was very intuitive. He knew how to do it and, when he pushed himself, could explain how he did it, sort of (see his essays collected in Hughes, 1984). I grew up in an era of methodological self-consciousness and thus was pushed to be reflective, more than he had ever been, about how I was doing what I was doing. 
I always begin a project, as I did in the case of Art Worlds, with a strong awareness of what I don't know. My sense of the topic is fuzzy, I'm sure I'm not asking the right questions, and equally sure that, whatever the question or problem finally turns out to be, that I don't know the right methods for studying it. And I am always-I don't brag about this but simply recognize that it is what I do-arrogant enough to ignore most of what people have already written about whatever I am about to study.

This is not to say that I have no idea at all. I dislike the way people imagine themselves going into the field as a tabula rasa, waiting for things to "emerge." That's grammatically wrong. Topics and problems and themes do not "emerge." It's better, though it's an awkward expression, to say that we "emerge" them, invent them as a result of what we learn once we begin our work. This means using what we learn each day, applying all the theories we have to each day's findings and then, on that basis, generating new problems and questions. We do that with the help of working ideas, what Herbert Blumer (1969, pp. 147-52) called "sensitizing concepts." The connection between theory and research, put simply and abstractly, is that theories raise questions, suggest things to look at, point to what we don't yet know, and research answers questions but also makes us aware of things we hadn't thought of, which in turn suggest theoretical possibilities. I'll give examples of this working back and forth between theory and data later.

Among the working ideas that guide me, once I begin to look into something, three are most important:

1. The idea that what sociology studies is how people do things together, what I learned from Blumer (1969, pp. 70-77) to speak of as "joint action." (I prefer to say "collective action," but mean the same thing by it.) This means that I always look for all the people involved in whatever I think I am studying, including especially the ones conventionally thought not to be very important. And, further, that I treat everything related to my developing topic-including especially all the physical artifacts-as the product of people acting together. A big research question is how they manage to coordinate their activity so as to produce whatever its result is.

2. The idea of comparison, that you can discover things about one case by looking at another case that seems similar in many ways but isn't quite the same. Placing two or more such cases side by side lets you see how the same 
phenomena-the same forms of collective activity, the same processes-take different forms in different places, what those differences depend on, and how their results differ.

3. The idea of process, that nothing happens all at once, that everything occurs in steps, first this, then that, and that this never stops. So what we take as an end state to be explained is only a place we have chosen to stop our work, not something given in nature (see Becker, Faulkner, and Kirshenblatt-Gimblett, 2005). The sociological analysis consists of finding, step by step, who did what, how they accomplished the coordination their activity required, and what came of their collective activity.

I used my year of freedom in Palo Alto to do much of the basic research for what became Art Worlds. This research took two forms-intensive reading and personal experience-and consisted of an oscillation between things I learned about how art works were made and ideas I had about what these observations meant (that's how I think of theory). To repeat, the most important general guiding ideas were that art was, in some way I would discover, collective; that art works resulted from a process; and that comparison would be central to my investigation, that I would always be comparing this art form to that art form, this way of doing things to that way, and that I would expect that comparison to show me important features of what I was studying.

I had been a piano player in bars and nightclubs and striptease joints since my teens, and I knew, from these experiences and other experiences I had had elsewhere in the arts, that works of art got to be what they were through a network of coordinated activities carried on by a lot of different people. My intuition used these experiences to tell me that studying such networks and activities would be a fruitful way to approach art. Still, I thought I needed some new experience to reflect on. The area I knew least about from my own experience was visual art-not being able to draw well had left me traumatized since elementary school (see Becker 1998, pp. 132-38)-so I took a class in photography, a visual art that did not require drawing, at the San Francisco Art Institute. I got very involved in making photographs and in the then very active photographic world of the San Francisco Bay Area the school introduced me to. Photography became a laboratory in which I could explore my ideas about art worlds. What I learned about the world I was inhabiting from day to day gave me an- 
swers for which, so to speak, I had no questions, as well as answers to questions I had already formulated.

So, to get down to specifics, I learned for myself, in the darkroom, how photographers depended on the materials they (and I) bought at the photo supply store. I first learned to make photographic prints on a very lovely paper made by Agfa, called "Record Rapid." Within months of my learning the rudiments of printing on this paper, Agfa stopped producing it, and it soon became clear, when I switched to printing on Varilour, made by DuPont, that printing on any other paper would mean learning again how the paper reacted to different exposure and development times. In case I had not learned the lesson, DuPont soon stopped making Varilour, and I had to change again. (With the coming of digital photography, all this hard-earned knowledge was quickly outdated, but that's another story.) I was not, of course, the only one inconvenienced when these companies dropped their products. Many professionals, for whom this was more important than it was to me, had similar troubles. In fact, as I learned, when platinum-based papers for printing, once used routinely by many photographers, were no longer manufactured, a few diehards continued to print on it, but now they had to make their own paper, sensitizing it with a platinum solution.

I also took advantage of pieces of "data" my ordinary contacts in the worlds of the arts produced. A friend, Susan Lee, was head of the program in dance at Northwestern University, where I taught. She told me stories about dancers who had been injured when stagehands, failing to clean the stage properly, created danger by leaving pieces of debris around that caused falls. An art dealer I knew casually told me a story of one of "her" artists who had delivered a work to a museum only to find that it was too big to go through the museum's doors and too heavy for its floors to support.

My theoretical use of such findings (and I had many similar ones) consisted of generalizing the thing I had observed. Well, what had I observed in my printing experiences? That artists used to working with a particular material would become dependent on that material. When it became unavailable, as when a manufacturer no longer made it, they might start using some other material they were not used to or they would fabricate what they could no longer buy themselves. The results would be different, but the photographers would not stop working; they would live with the change. Either way, the theoretical position that was not 
tenable, based on what I was seeing and experiencing, was a straightforward functionalism, which held that, say, material $\mathrm{X}$ was necessary for making art works of type $\mathrm{Y}$, so that if $\mathrm{X}$ becomes unavailable, $\mathrm{Y}$, no longer possible, will cease to exist. The theoretical revision is a small change in wording, but one that has serious consequences: when material $\mathrm{X}$ is unavailable, the artist can (a) make the material himself, (b) find someone new to make it, or (c) do without it. If he does without it, the work will no longer be what it might have been, but that doesn't mean it won't exist. In other words, it's not all or nothing.

This theoretical result works on the largest scale. It is true not only for something specific and, after all, trivial, like the paper photographs are printed on. In principle, the results hold at the most general level as well, even for whole societies, the phenomenon functionalism always really wanted to generalize about. So, what happens when family forms on which other elements of the society are thought to depend are disrupted or totally changed? Will the society cease to exist? That's the implicit or explicit prediction of a serious functionalism. I would say that what holds true for a photographic print made on platinum paper holds true here as well-you can say that the society will cease to exist in the form for which that kind of family was necessary, but the society will not disappear. It will be different, but that's not the same thing as disappearing.

In addition to doing this sort of casual observation by participation, I read a lot. My first theoretical thoughts about art arose from some discoveries in fields outside sociology. I had found, through the kind of random and undirected reading I learn most from, several books about music, literature, and visual art that contained ideas that meshed with my own theoretical dispositions. Leonard Meyer's Emotion and Meaning in Music (1956) used the idea of "convention"-an artificial but agreed on (as we later learned to say, "socially constructed") way of doing somethingto analyze the way composers and players used conventional patterns of melody, harmony, and rhythm to create emotional tension and release, and thus musical meaning. Meyer's colleague, Barbara Herrnstein Smith (1968) showed how poets similarly used conventional devices to indicate when a poem was finished. And Ernst Gombrich (1960), the esteemed art historian, had analyzed how painters indicated, through the use of conventional techniques, "real" trees, people, and other objects (William Ivins [1953] 
had done something similar in his analysis of techniques of etching and engraving, and I knew that book too).

"Convention," as these people used the idea, referred to things that the people who made art and the people who read or listened to it .or looked at it shared-to ways of seeing and hearing that were known by everyone involved and thus formed the basis for their collective action. And when I saw that these scholars were talking about the same thing I was-that "collective action" and "convention" were the same thing-I knew that I could use all the detailed research they had done as raw material for my own work. That gave me the courage to go on.

I had a piece of theory, if I can dignify it that way, to guide my reading. Fieldworkers know that complaints are especially good data about organizational activity. Why? Because organizations consist of (here's the theory) regularized ways of interacting, ways known to everyone taking part as the way things are done. Participants take these ways for granted-they are what I was calling "conventions" in the study of the arts-and are upset when others do not behave as expected. And they complain, their complaints making clear what had been taken for granted as "the way things are done here," which is, after all, what a sociologist wants to know.

Guided by this small piece of theory, my reading took a different turn and became a kind of fieldwork. I began looking for raw (or "rawer") data. Guided by my axiom that social life is collective action, I looked for material that told me who all the people were who helped in any way to make a work of art. I especially looked for autobiographical materials-books on the arts by participants in them-and especially for books filled with complaints about organizations and fellow workers. These were easy to find. Almost any book about the arts is filled with such material. Hollywood composers complain that producers, who commission film scores, don't know anything about music and make impossible requests that cannot be fulfilled (Faulkner, 1983); painters complain about the difficulty of finding the materials they want or about collectors and gallery owners who don't pay what the artists feel their work is worth (Moulin, 1967); publishers complain that authors make endless changes in their books, and authors complain that publishers don't publicize their books adequately.

Other books investigated the activities of people usually thought subsidiary to the "real" work of art. So Sutherland (1976), a literary analyst, showed how publishers played an important part in 
the construction of Victorian British novels, and Harmetz (1977), a film journalist, systematically explored the contribution of everyone who had anything to do with making The Wizard of $\mathrm{Oz}$ the seamstresses who made the costumes, the little people who played the Munchkins, but especially such key personnel as the composers of the musical score, who not only, as she shows, provided such continuity and coherence as the film has (the director, who might have done this, was replaced several times) but also were responsible for the important idea of filming the early sequences of the film, which take place in Kansas, in black and white, and changing to color when Dorothy arrives in the Land of $\mathrm{Oz}$.

Was I just collecting anecdotes, cute stories to make my dry theories "more interesting"? Not at all. I'll explain here the basic method I used then and still use to develop my ideas with the help of empirical instances like these.

In the case of art (but it's the same for anything I want to think about), I first list what Everett Hughes described as the cast of characters, all the people who might reasonably (or even unreasonably) be said to contribute to the event or object I want to analyze (the film, the novel, the musical or theatrical or dance performance). It's particularly important not to be blinded by convention here. Are stagehands part of the collective effort that creates ballet? Are ticket sellers and parking garage attendants? Most people, I think, would think it unreasonable to add these people to any list of crucial participants. But without them the show would not go on. So I include them. (The most inclusive list conventionally produced is the list of film credits that follows any feature film.)

Having made my list, I look for trouble, as earlier described. This tack is also unconventional. Most analysts regard troubles and difficulties as perhaps inevitable but by no means central to the understanding of a work of art, and maybe not even a very nice thing to look into. I make them central, supposing that by so doing that I will find the basic forms of cooperation that make the art possible.

And then I follow the two other ideas I described as central: process and comparison. I'll combine these by describing how I used an experience I had as I learned photography during my year in Palo Alto, an experience that shaped my understanding of the nature of works of visual art and, beyond that, works of art of all kinds.

Photographers usually make many more exposures than they 
actually use. When I learned to make pictures, before digital photography had been invented, they shot rolls of of film; usually, for those using $35 \mathrm{~mm}$ cameras (which most photographers used), thirty-six exposure rolls. They typically made many exposures of the same objects, places, people, and events. At an extreme, the photographer might use a camera fitted with a motor drive (especially when shooting sports events) and might make dozens of exposures of the same event in quick succession. After they developed the film, they made what was called a "contact sheet" or a "proof sheet," showing each of the thirty-six exposures. This gave them a convenient way of inspecting what they had done.

Most photographers considered this stage of inspection, when they chose among the many exposures they had made of the same or similar matters, crucial. They would decide which of the many similar images was the one they wanted, the one where the light or the framing or the arrangement of people and their expressions or of objects best conveyed what the photographer now decided was the thing to convey. This process of decision making, which photographers called "editing," produced the raw material for the next step in the process, which was making prints from the chosen negatives.

As I learned more about photography, I also learned that printing involved many similar small decisions: about the degree of contrast in the paper you chose to print on, about how long you exposed the paper to the enlarger's light and how long the paper remained in the developing solution-all of these contributing to differences in the final photograph. These differences were, in the end, substantial, creating quite different-looking images with quite different meaning and emotional effect. So my initial commitment to the theory of process was vindicated by showing up here in such an explicit way in photographers' work.

Don't think that all I needed to learn to arrive at the role of process was this one thing about photography. Think of what I've just described, rather, as a metaphor for the accumulation of the hundreds of similar things I learned about all kinds of arts. Here is where the operation of comparison comes in.

The key element in the process of editing that photographers engaged in was choice. At a crucial point-the weeding out of large numbers of exposures-the photographer made choices, which then influenced the resulting work. And this process of choice continued. It's not just one choice that influences the final image; it's a continuing series of choices. Well, I could and did ask 
myself, let's suppose that a similar process of choice affects other art objects and events in a similar way. The research question thus became for me, as I continued my reading and informal investigations, who makes what choices about a work and with what results?

Another book seriously influenced my thinking: J. H. Sutherland's account (1976) of the relations between publishers and authors in nineteenth-and early twentieth-century English literature, the relations between such esteemed novelists as Charles Dickens, William Makepeace Thackeray, George Eliot, and Thomas Hardy and the men who published their books. Sutherland's extensive investigations of the archives of publishing firms revealed that publishers interfered extensively and consequentially in the works they published. They suggested changes in plots and language, insisted on formats that maximized profits from sales to the then ubiquitous lending libraries, and in many other ways affected the content and style of the books they published.

Sutherland's examples taught me that other people besides the putative artist were consequentially involved in the editing process, making choices that helped shape the resulting work. And I carried the comparative operation on with this in mind. Further examples were not hard to find: film editors and composers of film scores, gallery owners and museum curators, literary editors, and so on and so on. I finally saw the list of credits at the end of a big Hollywood film as the ultimate symbol of the cooperative networks that made the art I was talking about.

Comparison consists of finding something in common between two things and then looking for how they differ. Both operations are analytically important. The similarity, in the case of the editing process, lay in the idea of choice, in seeing that art works did not simply pop into existence but were constructed a piece at a time, by the making and placing of every piece. But finding a similarity led immediately to looking for an underlying dimension of difference. Looking at the differences between examples-between, say, photography and writing novels-produces different versions of that process, introduces different actors, and emphasizes different steps. The physical process of making the work is more present for photographers, and all the choices involved seem to be in their hands, while novelists typically produce an original whose copies are made by other people using different kinds of machinery and different production processes (not that authors don't complain about the physical results!). The two aspects of 
the comparison open up new questions for investigation, new roads to follow in later work.

Writing a book like Art Worlds is itself a process. I didn't set out to write a book about art. I only wanted to explore my intuition that art was a collective activity and see where that led. Once I became interested in the topic, I began to teach a class in the sociology of art, which was then not so common a topic as it has since become. Giving lectures every week on one or another aspect of what had interested me in my reading and reflection on my own experiences created a framework, an outline of topics. The necessity of interesting students also led me to create little set pieces I could do in class: the story of the man who built the Watts Towers in Los Angeles fascinated students and became the kernel of the chapter on mavericks and their art.

As I accumulated examples, compared them, taught about them, and created the framework that could put them in some coherent order, I began to envision papers on this or that aspect of the process. I wrote these papers partly because they told me they wanted to be written, but also in response to invitations to speak here, participate in a conference there, contribute an article to a book or journal. Each request seemed like a summons to do something I should do, though of course I had no obligation to do any of it.

After several years, I had accumulated seven or eight articles on various aspects of what I now saw as a sort of unified theory. I laid the articles I had done out on the floor and saw-it was a visual discovery as much as a product of rational thought-where the holes were and what I would have to write to fill them up.

I finally had to confront the question that is probably the single most difficult one for any writer to answer: when am I through? Is this research done? Is this book done? How will I know? Isn't there always one more thing that must be done? (See, again, Becker, Faulkner, and Kirshenblatt-Gimblett, 2005.)

With Art Worlds I did not have to worry about whether I had done enough interviews or observation. My data, my examples, only had to cover a wide enough variety of situations and art forms so that I could feel I was not leaving out anything obvious that could make my analytic framework more complex. Complexity was my goal, not generalizability. Or, rather, my generalizations were going to be about what was possible, what would be worth looking for in an investigation of artistic activity. So, in essence, I just had to decide when enough was enough. 
I solved the problem by starting to think about my work on the question of art as collective activity as itself a process, in which writing a book was a stage, but not the last stage. The book was, rather, a progress report on a line of work that extended into the future. My generalizations might be wrong or incomplete, but they were, after all, provisional, as all scientific conclusions necessarily are (see Latour, 1987).

So I never intended to provide a comprehensive Theory of Art, the capital letters signifying unity, completeness, definitiveness. That has never been my idea of theory. To me theory is a more or less coherent set of ideas that tell me what to look for as I continue my investigations of a topic, and that was what I expected Art Worlds to provide, to me and to anyone who read it and thought the ideas worth pursuing. In the best Kuhnian sense (Kuhn, 1970), the object of the book was to provide a framework that would continue to generate researchable ideas.

The project continues, to this day, as I continue to explore some of those researchable ideas. But it also involves, as the ideas in the book suggest, other people. This is not the story of a heroic thinker working in isolation to create a new vision and bring it to fruition. No such Romantic events are involved. When I wrote Art Worlds I found people to think with-all the authors I consulted, some of whom I have mentioned here, and also the people I talked to who were actively engaged in art work and with some of whom I collaborated, as a student or colleague.

I continued looking for colleagues that way, but also found people with whom actually to cooperate on specific projects. I'll trace out one such line of work that came into being after the book.

My early work on the book had led me to become interested in the work of French sociologists of art. The only one known in the United States at the time was Pierre Bourdieu, but I was much more interested in the more ethnographic and exciting work of Raymonde Moulin. She had written a book on art markets in France in the mid-twentieth century (Moulin, 1967) that I possessed but could not read, because at the time I did not read French, though I had passed an examination for the doctorate certifying that I could. I taught myself to read French in order to read Moulin's study, and this led to meeting her, to being invited to spend a month at her Centre at the CNRS, and thus meeting Pierre-Michel Menger, Dominique Pasquier, Sabine ChalvonDemersay, and other sociologists of art, many of whom also gave 
me books and papers in French to read. The more I read, the easier it was to read still more.

Then Alain Pessin invited me to Grenoble to take part in a conference on the "sociologie des oeuvres" (Majastre and Pessin, 2001). I wrote a paper for this meeting ("Loeuvre elle-même") that explored the implications of the argument in Art Worlds, that works of art have no stable existence but are continually changing. This topic continued to occupy me, and when I had an opportunity to organize a conference on the sociology of art for the Social Science Research Council of New York, I made it the focus of our meeting. A number of social scientists and humanists collaborated in this venture to produce a book of essays (Becker, Faulkner, and Kirshenblatt-Gimblett, 2005) exploring various facets of the problem (two of the papers on which the conference was basedmine and Menger's-had been presented at the Grenoble meeting). And, by no means least, as Robert Faulkner and I discussed the paper he was presenting at the conference, which dealt with the way jazz players practiced, we discovered a topic we both wanted to work on: the jazz repertoire, how it came into being and was maintained and deployed in the ordinary working life of musicians. We are well started on this project now.

I don't mean to recommend to researchers wanting to know when their work is done that they learn a new language, find new colleagues, and do more research. The lesson I draw from my experience is, rather, that we are never through, but occasionally stop to tell our colleagues what we have learned. 
